\title{
CORRESPONDENCE.
}

\section{ON CERTAIN STATEMENTS PUBLISHED BY MR. FILIPOWSKI.}

To the Eator of the Assuranee Magazine.

Sin,-May I crave a portion of your space for the elucidation of a matter somewhat personal to myself?

Upwards of eight years ago I published my modification and extension of Gauss's Sum and Difference Logarithmic Tables. Some months thereafter, Mr. Filipowski published his Anti-Logarithmic Table, having also appended to it a modification and extension of Gauss. In his introduction, Mr. Filipowski-seeking, in accordance with a common practice of authors, to show that his tables were needed-institntes a comparison between his Gauss and mine; in which comparison, as might have been expected, he makes it ont that his is free from objections to which mine is open, and that, consequently, his is superior to mine. Had Mr. F. contented himself with merely giving us his affirmation to this effect, I should most likely have been satisfied to leave the matter to the decision of those who might have occasion to ase the tables; bnt he invites criticism by stating the grounds on which he claims this superiority. Even so, however, all I did, when the matter came first ander my notice, was to call Mr. F.'s attention to a single point in regard to which be showed, in my judgment, an entire misapprehension of the facts of the case. I did not succed in showing him that he was wrong, and I thonght no more of the matter. Recently it has again been brought under my notice; and on reperusing Mr. F.'s statement, I consider it such as to call for a few remarks from me.

Mr. Filipowski says, p. xiv.- "Another table of this description, to six places, was published this year by Peter Gray of London. In this latter pnblication, the whole table of Ganss has been remodelled. In the first place, the column headed ' $\log . x$,' answering to colnmn $A$ in that of Gauss, goes only to $2 \cdot 0$ altogether; consequently, confined to such two numbers whose difference must not exceed 100. Secondly, it has been divided into two separate tables, the one intended for $(a+b)$ and $(a-b)$, and the other for $(a-b)$ only, by which rearrangement was gained nothing. Instead of reducing the three methods of Ganss to two, they were left nnaltered, the process by subtraction not being avoided. Nor has there been removed the obstacle which, in the application of his table, will occasionally canse an error, as in that of Gauss; especially where the ratio of $a$ to $b$ approaches a ratio of equality-namely, where the difference of the two given logarithms is near 0.30103 , as was mentioned above. The author himself, page 11 of his work, after giving three methods for the case of $(a-b)$ alone, says: 'We have thus three modes of solution of Problem I.' (alluding to the case of $(a-b)$, 'but all are not applicable thronghont the same limits-that is to say, in many of the cases that arise in practice, some one or other of the methods may not armit of being applied, in consequence of the argument being beyond the limits of the series in which, in the use of those methods, it has to be songht. The second method applies to all the cases to which the first applies; and it is generally to be preferred, as being at least as correct as the others, and also somewhat easier. The results of the third method, where it alone is applieablenamely, towards the commencement of the table, where the ratio of $a$ to $b$ 
approaches a ratio of equality--must be used with caution. The deviation from the truth, in the results arising from the inverse use of that part of the table, will often be very considerable.' To remedy this great inconvenience, an entirely new arrangement of the above table has been introduced, by which the three modes of solntion for both cases of $(a+b)$ and $(a-b)$ are reduced to two only; and both, without exception, are effected by addition."

1. Mr. F. says, my column headed "log. $x$ " goes only to $2 \cdot 0$, and is "consequently confined to such two numbers whose difference must not exceed 100." Now it is true that my table extends only to $2 \cdot 0$, but no such consequence as is here stated arises. It is not confined in its applications to numbers whose difference does not exceed 100. The difference of the numbers may be any whatsoever. The table is still applicable, provided their ratio does not exceed that of 100 to 1 . My example 6 (p.6) shows the application of the table to two numbers whose difference is upwards of 20,000. Had Mr. F. therefore written ratio instead of difference, he would have been right; but as he declined to receive this as a correction when I suggested it to him, he may, I suppose, be considered as persisting in his misdescription.

2. He says I have "divided" Gauss's table into "two separate tables." This is a mistake-my second table is not after Ganss at all; it is, as distinctly stated in my preface (p. vi.), an entirely new table, compnted by myself.

3. Mr. F. makes it an objection to my tables that I give three methods for the solution of the second problem, viz., to find $\log$. $(a-b)$. New, I believe, will take the same view of the matter that he seems to do. My first method involves the use of Table I. It is the same as Mr. F.'s, and, like it, is applicable through the whole extent of the table. My second and third methods involve the direct and the inverse use of Table II., and are applicable, one or other of them, from the nature of the data, throughout wider limits than those to which the first method is restricted. My second table was computed precisely with a view to this extended applicability; and it appears to me to require a pecnliar idiosyncrasy to make it a gronnd of objection to an instrument, that it affords too many facilities for the purpose it is intended to serve.

4. Mr. Filipowski very plainly implies, that in my methods for the formation of $\log$. $(a-b)$ I make use of snbtraction where he employs addition. It is not so. All of them, like his own, consist of a subtraction, a tabular entry, and an addition. It seems clear to me that he has not mastered my methods.

5. Mr. F., by calling particular attention to the caution I found it my duty to give, as to the degree of dependence to be placed, in certain circumstances, on the results of one of my methods, leaves it to be inferred that his own method, in like circumstances, will give more satisfactory results. To test this I take an example, nearly at random. Given log. $a=1 \cdot 854452$, and $\log . b=1 \cdot 848337$; to find $\log$. $(a-b)$. And I subjoin the two processes-Mr. F''s on the left, and mine on the right.

\begin{tabular}{|c|c|c|c|}
\hline 1.85445 & & 1.848337 & \\
\hline $\begin{array}{l}1 \cdot 84834 \\
8 \cdot 151\end{array}$ & 0.00611 & $\begin{array}{l}1 \cdot 854452 \\
\frac{2}{2} \cdot 145600\end{array}$ & $\begin{array}{r}\overrightarrow{\mathbf{1}} 993885 \\
93\end{array}$ \\
\hline $9 \cdot 99934$ & & 0.000052 & 8 \\
\hline
\end{tabular}


Here the numbers whose logarithms are given are 71.524, and 70.524; and their difference being 1 , the result therefore ought to be 0 . Mr. F's process shows an error of 66 in the last two places, and mine shows an error of 52. It is quite possible that in another trial the state of the errors might be reversed; but the truth is, the error in both cases arises from the nature of things. The data are insufficient when the numbers are nearly equal; and the insufficiency is indicated, in both tables, by the state of the differences, at the part in use, in the two series of which each table consists. In both tables the ratio of the differences at the part that here comes into operation is abont 70 to 1 ; the less of the two being in the series that here forms the argument. Any error in the argament will consequently prodnce an error seventy times as great in the result.

I much fear it will be considered that I have attached undue importance to a very small affair. I therefore add no more as regards my personal concerns. Ere I close, however, I must enter my protest against a systematic abuse of the algebraic sign of equality practised by Mr. Filipowski. Thus (p. 202) we find-

$$
\lambda a=0 \cdot 638783=\mathrm{N} .4 \cdot 35240 .
$$

The recognized interpretation of the latter part of this expression is " 0.638783 is equal to the number 4.35240 ," which of course is not true. If it must be written as an equation, the established form is

$$
\begin{aligned}
\lambda^{-1} 0 \cdot 638783 & =4.35240 . \\
\text { I am, Sir, } & \text { Your most obedient servant, }
\end{aligned}
$$

London, 11th Mareh, 1858.

P. GRAY.

\section{FORMULA FOR APPROXIMATING TO THE EXPECTATION OF LIFE.}

To the Editor of the Assurance Magazine.

SIR,-The prblication of $\mathrm{Mr}$. Willich's formula, expressing the expectation of life according to the Carlisle Table of Mortality, indnces me to forward you the following memoranda, extracted from my Note Book, for insertion in your next Number, if you think them likely to be neful to your readers:

If the letter $a$ signify any given age, the expectation of life at that age, according to the Northampton Tables, is, approximately, and from the age of 5 to $70, \frac{86 \frac{1}{4}-a}{2}$.

According to the Government Table for Male Lives,

for Female Lives,

$$
(85-a) \frac{3}{5}, \text { or } 51-\frac{3 a}{5}
$$

$$
(86 \cdot 4-a) \frac{2}{3} \text {, or } 57 \cdot 6-\frac{2 a}{3}
$$

According to the Carlisle Table, from 7 years to 76 ,

$$
57-\frac{5 a}{6}+\frac{a^{2}}{450}
$$

This is correct within half a year, excepting from the age 57 to 64 , where the error is somewhat greater. It gives a value slightly higher than 